\title{
LOGO
}

\section{O ESPECTADOR ATIVO EM EXPOSIÇÃO: UMA EXPERIÊNCIA DE INTERAÇÃO COM A ARTE NO ESPAÇO EXPOSITIVO}

\section{THE ACTIVE SPECTATOR IN EXHIBITION: AN INTERACTIVE EXPERIENCE WITH THE ART IN THE EXHIBITION SPACE.}

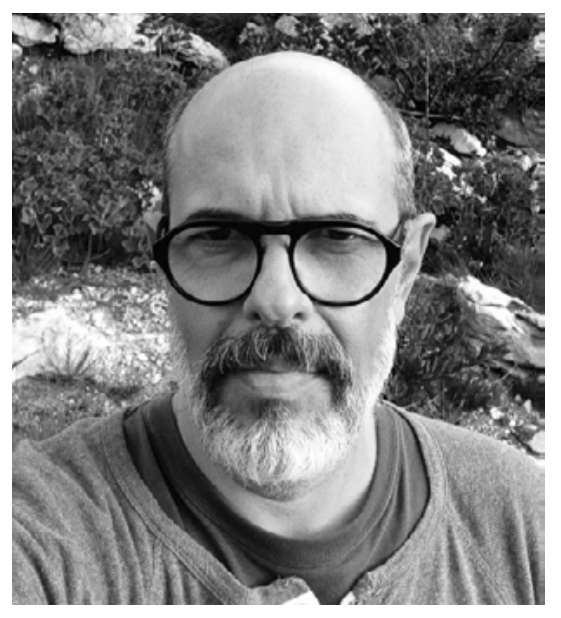

\section{Marcos Martins}

Doutor em Comunicação pela Universidade Federal do Rio de Janeiro.

Professor Adjunto da Escola Superior de Desenho Industrial ESDI/UERJ.

marc.a.martins@gmail.com

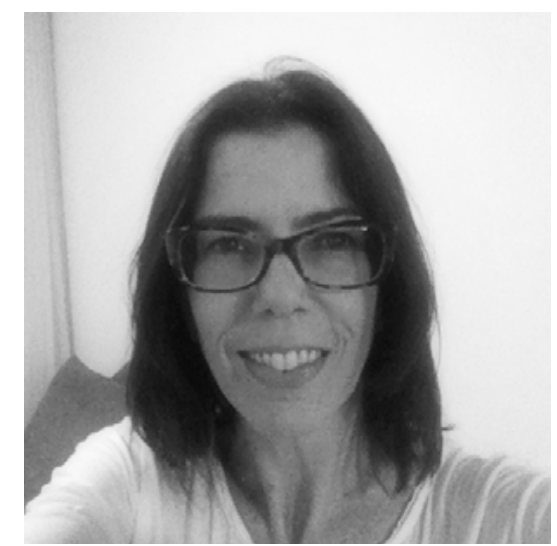

\section{Renata Perim A. Lopes}

Mestre em Artes Visuais pela Universidade Federal do Espírito Santo.

Doutoranda no programa de pós-graduação em Design da Escola Superior de Desenho Industrial ESDI/UERJ reperim10@gmail.com 


\section{RESUMO}

Este artigo apresenta uma análise da experiência do espectador em exposições, verificando sua relação com os novos meios de interação com a arte. $O$ corpus analisado será composto por fotos selecionadas no aplicativo Instagram. Tomamos como ponto de partida fotos capturadas por parte do público visitante da exposição Picasso e a Modernidade Espanhola, em sua versão apresentada no Rio de Janeiro em 2015. Foi analisado o conjunto de fotos organizadas por meio da hashtag \#modernidadeespanhola. A análise da narrativa criada nesse meio mostra as características da exposição e do próprio observador.

\section{PALAVRAS-CHAVE:}

Espectador. Fotografia. Exposição

\section{ABSTRACT}

This paper presents an analysis of the viewer's experience in exhibitions, by verifying their relationship with new medium interaction with the art. The analyzed corpus is composed of selected photos in the Instagram application. We take as a starting point pictures taken by the visiting audience at the exhibition Picasso and the Spanish Modernity, in its version presented in CCBBRJ (Rio de Janeiro, 2015). It was analyzed a set of photos organized by the hashtag \#modernidadeespanhola. The analysis of the narrative created in this medium shows both the exhibition features and the observer himself.

\section{KEYWORDS:}

Audience. Photography. Exhibition

\section{INTRODUÇÃO}

O espaço expositivo vem se transformando, nas últimas décadas, não só pela inserção de tecnologias que hoje se misturam com as obras de arte em museus e galerias, mas também pela nova atitude do público dentro desses espaços. Não se trata aqui de explorar os novos procedimentos museográficos - como as telas touchscreen, projeções de imagens e vídeos ou o audiovisual - cada vez mais presentes em exposições. Nosso objetivo é reconhecer a capacidade de alteração do espaço de exibição a partir do olhar do espectador mediado pelas tecnologias correntes. Trata-se de explorar os dispositivos móveis com câmeras fotográficas que são levados para dentro dos museus e possibilitam o registro da exposição pelo espectador. Em particular, analisamos o uso do 
aplicativo de armazenamento de fotos Instagram', que permite aos usuários manipular, adicionar tags e compartilhar fotos. Destacamos as imagens compartilhadas pela hashtag \#modernidadeespanhola criada na ocasião da exposição itinerante do artista Pablo Picasso em sua versão montada no Centro Cultural Banco do Brasil (CCBB-RJ).

Apesar da exposição apresentar a obra de uma figura central da arte moderna, houve o cuidado de não se ofuscar o artista em função de sua própria lenda: "a tendência foi a de situar a produção do artista espanhol numa série de contextos que removem Picasso de sua posição anterior entre o heroico e o lendário, situando-o num novo espaço de inter-relação com outros criadores e narrativas" (BORJAVILLEL; PEIRÓ, 2015). A mostra contou com obras de outros artistas, representantes do modernismo espanhol, que dialogam com o trabalho de Picasso.

Todo o aparato de interação construído na exposição - em especial Labirinto dos Espelhos, destacado mais adiante - parece ter tido a função de apresentar a multiplicidade de sentidos que emerge da obra de Picasso. Essa também era a função do próprio movimento cubista: lançar uma reordenação do olhar moderno. Nesse sentido, as imagens da exposição produzidas e compartilhadas em um novo meio, respondem à proposta da montagem da mostra que buscou inserir novos olhares e conceitos sobre a obra de Picasso.

Interessa analisar como o compartilhamento de fotos pode revelar uma narrativa da exposição, e como os espaços expositivos são transformados e ampliados pelo olhar do espectador atravessado por dispositivos de captura. Perguntamos: o que essas imagens capturadas nos permitem ver? Que diferentes visualidades são criadas a partir das imagens produzidas por esses espectadores?

\section{O PÚBLICO: ESPECTADORES ATIVOS}

A organização espacial de uma sala de exposição tendo como referência o espectador vem transformando, ao longo dos séculos XX e XXI, continuamente o espaço expositivo. Marcel Duchamp, já em 1917, participa efetivamente da transformação dos espaços expositivos. Referenciamos Duchamp não só pelos Ready-mades, o Grande Vidro e o Étant Donné, mas também pelo seu entendimento desse processo de transformação. Duchamp projetou exposições nas quais a interação entre o artista, a obra de arte e o observador era crucial. A captura e a expansão de uma subjetividade por meio do compartilhamento

1 O aplicativo Instagram foi lançado em 2010, conta com mais de 400 milhões de usuários e é uma das redes sociais mais populares do mundo. Disponível na internet por http em: http://www.statista. com/statistics/ 253577/number-of-monthly-active-instagram-users/). Acesso em 16 mai. 2016 
de fotos parece quase reencarnar a frase de Duchamp: “(...) o espectador traz a obra para o mundo externo, ao decifrar e interpretar suas qualidades interiores, adicionando sua contribuição ao ato criativo" (GROSSMANN, 2011, p. 220). Nas exposições que organizou, o artista buscou explorar outras formas de fruição do espectador. Na mostra First Papers of Surrealism (Nova York - 1942) Duchamp fez intervenções no espaço de exibição utilizando fios de barbante em toda a área central da exposição. ${ }^{2}$

A atenção voltada para o observador, assim como a organização histórica e cultural da visão, foi foco dos estudos de Jonathan Crary (2012). O autor busca desenvolver relações entre o sujeito que observa e os modos de representação a partir de seus antecedentes históricos. Para Crary, a escolha do termo observador remete a algo mais pertinente ao seu estudo e traz para nossa análise contribuições no que se refere ao visitante de exposições. Diferente de espectador, "que carrega conotações como assistir passivamente a um espetáculo", o observador "é aquele que vê em um determinado conjunto de possibilidades, estando inscrito em um sistema de convenções e restrições." (Crary, 2012, p. 15). O observador seria uma consequência (ou um produto) de um contexto - social ou tecnológico - no qual estaria inserido.

É relevante apontar que o método de Crary baseia-se no destaque de uma série de aparatos, os quais, em determinado momento, produziram um observador inserido no contexto das novas demandas da sociedade industrial. Sendo assim, nossas análises se baseiam no que Crary entendeu como o"observador ambulante formado por uma convergência de novos espaços urbanos, novas tecnologias, novas funções econômicas e simbólicas das imagens e dos produtos" (Ibid, p. 28). Buscamos, neste estudo, entender como se dá a construção do espectador atual cuja participação, no espaço expositivo, pode ser cada vez mais notada ${ }^{3}$. A exposição de Pablo Picasso no CCBB, que nos serve de referência, recebeu o total de 620.719 visitantes e consta como umas das vinte exposições mais visitadas do mundo em 2015². Na era da computação ubíqua (WEISER, 1991)

2 Essa intervenção instalava uma espécie de barreira entre o espectador e a obra. Os fios eram passados de uma extremidade a outra, interferindo no espaço de passagem do público e nas obras em exibição: “O fio explorava todo o espaço implacavelmente" (O’DOHERTY, 2002, p. 79). 3 Técnicas do Observador (2012) foi publicado originalmente em 1990, período marcado pelo culto à tecnologia e em meio aos imperativos da globalização. A obra é apresentada aqui para inspirar modos de pensar sobre como a imagem é hoje observada e percebida no mundo contemporâneo.

4 IBRAM. Exposições brasileiras figuram em ranking das mais visitadas de 2015. Disponível na internet por http em:<http://www.museus.gov.br/exposicoes-brasileiras-figuram-em-

-ranking-das-mais-visitadas-de-2015/>. Acesso em: 15 mai. 2016. 
o uso da tecnologia para reprodução de imagens se popularizou também no espaço do museu. Parte desse público reproduziu, manipulou e compartilhou imagens do espaço expositivo e utilizou o Instagram como meio para divulgação de suas fotos. Havia um total de 544 imagens compartilhadas sob a hashtag \#modernidadeespanhola, dentro da qual estavam disponíveis para visualização aproximadamente 300 fotos. $^{5}$

A inserção de tags nas fotos pode estar relacionada a diversos fins, como o compartilhamento de informação, interesses sociais ou a expressão de uma opinião. O usuário almeja, invariavelmente, a recompensa individual: comentários e elogios expressos por meio textual ou por likes. Por outro lado, esse mesmo usuário, também visitante, proporciona uma nova configuração para o espaço do museu, agora deslocado para as pequenas telas dos telefones. A interface do aplicativo preenchida pelo tema da exposição amplia a ação do museu e da própria arte. Martin Grossmann (2011) se refere ao espectador como visitanteusuário-partícipe e enfatiza que ele atua na modelagem de seus espaços propondo novas formas de fruição da arte. Grossmann trata de questões da arquitetura e do programa de alguns museus, enfatizando que o projeto só se realiza por completo pela ação do espectador no seu interior.

A exposição de Picasso se desloca de seu lugar original para as pequenas telas dos dispositivos móveis. Esse deslocamento acontece quando o espectador, ao percorrer a exposição, registra imagens do espaço expositivo e as compartilha nas redes sociais. Walter Benjamin (1987) fala da autenticidade e da reprodutibilidade técnica da obra de arte e da fotografia. Benjamin demonstra em seu célebre ensaio o valor da reprodução técnica do original. O autor afirma que "a reprodução técnica pode colocar a cópia do original em situações que são inatingíveis ao próprio original" (BENJAMIN, 1987, p. 168). Ao considerarmos as imagens compartilhadas como "reproduções técnicas" e a exposição como o "original", é possível encontrar, nas fotos do Instagram, aspectos acessíveis somente a esse meio. A visão superior da estrutura espelhada, com os detalhes geométricos e a variação de ângulos, é um exemplo.

Embora ela pudesse ser vista durante a exposição, agora ela só vive por meio das fotos (figura 1), diferentemente de outras obras de Picasso, ou até mesmo da Mona Lisa, que continuam a existir independentemente de sua reprodução.

\footnotetext{
$5 \quad$ No Instagram, as fotos que podem ser visualizadas são de usuários que têm perfil no modo público. Para os usuários que definem seu perfil como privado suas fotos podem ser acessadas apenas pelos seus seguidores. Disponível na internet por http em: $<\mathrm{https}$ //help.instagram. com/442837725762581>. Acesso em: 14 nov. 2016.
} 

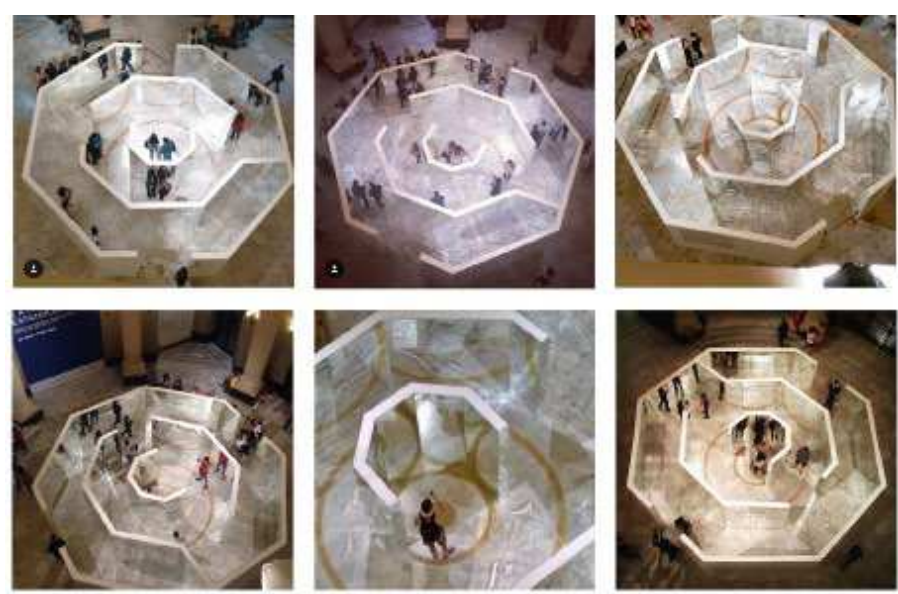

Figura 1 - Fotos da rotunda CCBB-RJ, exposição Pablo Picasso, 2015. Fonte: Instagram (\#modernidadeespanhola). Adaptado de: @ssaminima, @clebermacedo, @vanessa_a_lino, @ weslleypax, @lucianabarravieira e @ananeverslleps.

Uma vez que a visão do espectador é compartilhada, a exposição é levada ao encontro de outros espectadores e se insere no contexto de imagens cotidianas, passíveis de serem visualizadas a qualquer hora, inclusive após o término da mostra em seu espaço físico (Figura 2).

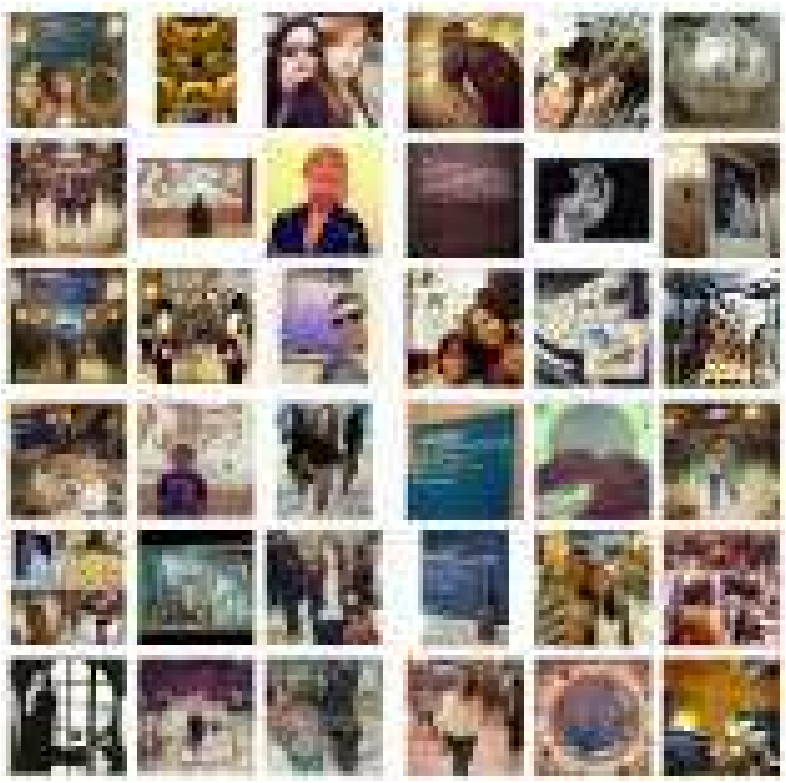

Figura 2 - Mosaico de fotos do Instagram (\#modernidadeespanhola). Fonte: Instagram

A coleção de imagens criada a partir de fotos enviadas pelos visitantes leva a perceber que a mídia - Instagram - e a fotografia dispõem de linguagens distintas e que se entrelaçam, quando visualizadas em conjunto. 
No Instagram, as imagens agrupadas parecem obedecer ao princípio de modularidade, apontado por Manovich, no qual "os elementos são montados em objetos de maior escala, mas eles continuam a manter sua identidade separada". (Manovich, 2001, p. 51). Podemos entender que juntas, as imagens oferecem uma visão geral da exposição, porém cada uma representa uma visão individualizada, com diferentes tags e comentários. Encontramos aí a possibilidade de algumas classificações. Separando imagens semelhantes, destacamos dois grupos: o autorretrato (selfies) e o espaço expositivo (identidade visual).

Antes de analisar cada um desses grupos, cabe refletir que ao olharmos a imagem fotográfica - autorretrato ou paisagem - somos levados a uma troca de experiências culturais. Num álbum de família ou tocando nos pequenos monitores do celular, estamos imersos em um sistema de informações que foi organizado e classificado. Para Susan Sontag,

Através da fotografia, encontramo-nos também numa posição de consumidores de acontecimentos, seja os acontecimentos que formam parte de nossa experiência, seja os que não - distinção entre tipos de experiência que esse consumismo dependente torna vaga (SONTAG, 2004, p. 150).

As fotos compartilhadas no Instagram podem funcionar como o prolongamento do tema fotografado e levam ao usuário, tendo ele a experiência presencial ou não, o conhecimento da exposição.

\section{AUTORRETRATO (SELFIES)}

Na mostra Picasso e a Modernidade Espanhola, os visitantes encontravam, logo no início, na rotunda do museu, uma estrutura espelhada em formas geométricas. Nessa estrutura os visitantes poderiam circular e fotografar suas imagens, individualmente ou em grupo, refletidas nas paredes espelhadas. $\mathrm{O}$ ambiente, chamado de Labirinto dos Espelhos, foi organizado como um cenário para que o público pudesse ver sua imagem no espelho com características da técnica cubista (Figura 3). 


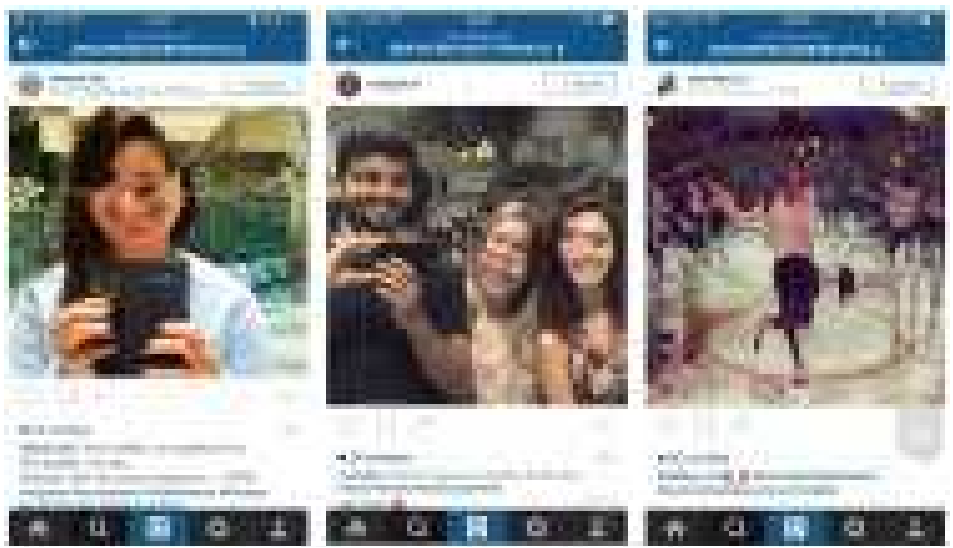

Figura 3 - Fotos selfies no Labirinto do Espelhos. Fonte: Instagram (\#modernidadeespanhola) @francis.lais, @madalferr e @sherillyn_m.

No Instagram percebeu-se que esta instalação gerou inúmeros selfies ${ }^{6}$. Tendo em vista as fotos organizadas no aplicativo, torna-se pertinente investigar a conexão e a construção das subjetividades dentro do espaço expositivo. Para Paula Sibília (2008), o que é primordial no conceito de subjetividade é a relação com o outro na constituição do eu. As experiências pessoais sempre têm relação com a interação entre as pessoas e o mundo. Podemos notar dois modos de interação implícitos no ato de se fotografar no Labirinto dos Espelhos. O primeiro refere-se ao uso recorrente do celular para captura de imagens, como mostra a repetição das fotos no local (figura 4).

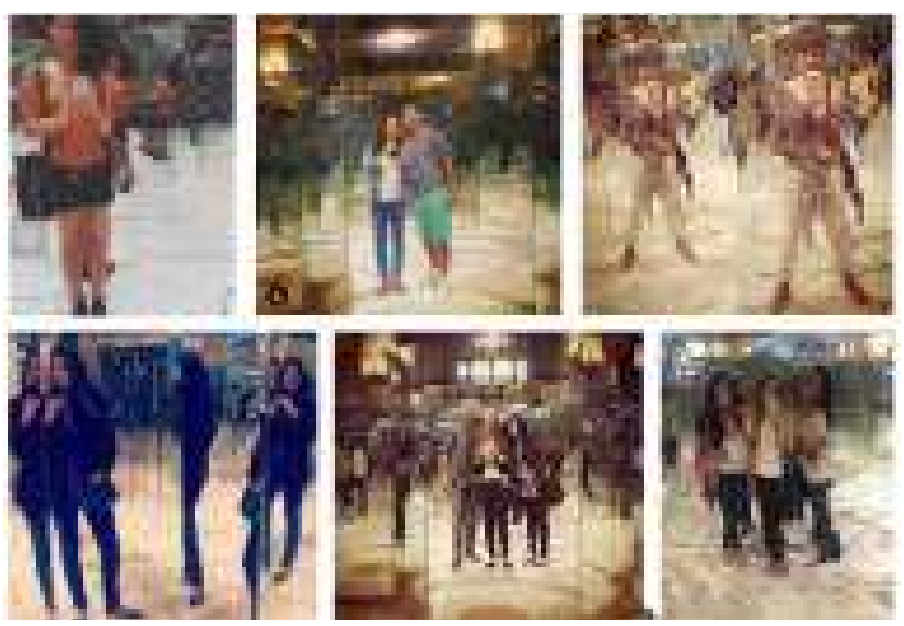

Figura 4 - Fotos selfies no Labirinto dos Espelhos. Fonte: Instagram (\#modernidadeespanhola) - @dioliveirapam, @fmerielen, @elis_santos, @viviisbraga, @_suzanee e @carol.lavrador

6 Fotografia que a pessoa tira dela mesma, tipicamente com um smartphone ou webcam, carregada em um site de mídia social. Disponível na internet por http em: http://www.oxforddictionaries.com/ us/definition/american_english/selfie. Acesso em: 14 mai. 2016. 
Poderíamos supor que esse tipo de interação remete ao conceito de automatismo - entendido por Rosalind Krauss como "regras que qualificam um meio e sobre as quais os participantes de uma determinada disciplina tinham a liberdade de improvisar" (KRAUSS, 2011, p. 16). Dentro da estrutura espelhada, parecia ser necessário o uso de dispositivos com câmera fotográfica e fazer uma foto da imagem refletida no espelho assemelhava-se a uma regra. Por outro lado, não poderia ser prevista a série de imagens produzidas em diversos ângulos e planos, individualmente ou em conjunto. A improvisação nessa parte da exposição foi bastante estimulada.

Outro tipo de interação do espectador é o compartilhamento dessas imagens nas redes sociais, especificamente no Instagram. Esse compartilhamento gera as interações já mencionadas, como os comentários e os elogios, e traz uma característica bastante presente na circulação de imagens em redes sociais, observada por Sibília como o ato de "montar o espetáculo daquilo que somos" (SIBÍLIA, 2013). Estamos falando de um espectador ativo que busca construir sua imagem dentro de um espetáculo, criando, na exposição, sua auto-exposição. Guy Debord (1992) usa o termo "espetáculo" como a tendência de "fazer ver". Ele afirma que "o espetáculo não é um conjunto de imagens mas uma relação social entre as pessoas, mediatizada por imagens" (p. 14). Seguindo com Debord, ressaltamos que as fotos selfies estabelecem uma relação que vai além do olhar para si, adquirindo o caráter de agência quando deslocam o ambiente do museu para outros meios.

\section{ESPAÇO EXPOSITIVO (IDENTIDADE VISUAL)}

Além das selfies, outro tema recorrente nas imagens compartilhadas com a hashtag \#modernidadeespanhola foi o da identidade visual da exposição. O título da exposição, composto por uma tipografia sem serifa, alinhado à esquerda, com letras brancas em fundo azul, foi fotografado como uma forma documental de registro. Os espectadores, aqui também observadores, assumem o papel de catalogadores, registrando o nome, o local e a data da exposição (Figura 5). 

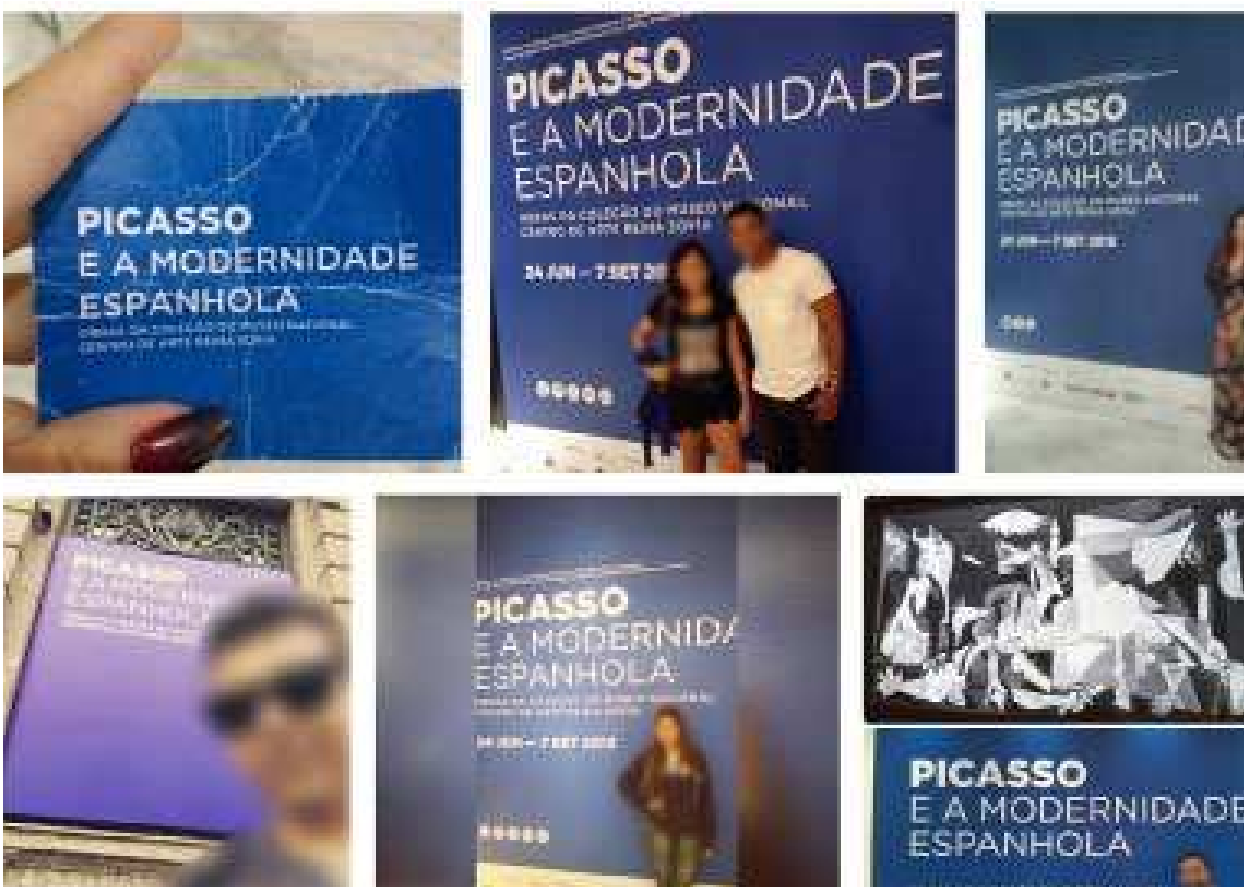

Figura 5-Fotos do espaço expositivo. Fonte:Instagram (\#modernidadeespanhola) - @tatitep, @oliveiralso, @clarah_iam, @milady_karinaviana, @guga_santtos10 e @barretoroomariz

Notamos que as fotos tageadas da identidade visual da exposição sugerem o sentido comunicacional de uma forma mais intencional que as fotos selfies, ou seja, parece existir aqui o sentido de contribuição institucional. De acordo com Moritz Steffaner (2007), "tags não são aplicadas somente para o benefício social mas também para a comunicação com um público maior, fornecendo uma contribuição para o processo estrutural colaborativo" (STEFANER, 2007, p. 41). Com isso, ao enviar a foto selecionada e aplicar a hashtag \#modernidadeespanhola, o espectador assume o papel de emissor de uma mensagem. Observamos nessas fotos que a composição quase sempre obedece a técnicas de comunicação visual - simetria, equilíbrio, hierarquia e contraste - aplicadas em anúncios publicitários ou em peças de design gráfico. Nesse caso, o processo de postar uma foto no aplicativo convida o espectador da exposição a diagramar, escolher filtros, enquadrar e iluminar a foto, atividades que, até há pouco tempo, eram exclusivas do designer e do diretor de arte. Poderíamos dizer que o visitante, ao mesmo tempo em que participa do processo de construção da própria imagem, contribui também para a divulgação e a promoção da instituição. Essa contribuição, embora se processe quase sempre de modo ingênuo, ou por diversão, acaba por marcar a presença da mostra no meio digital. E se entendermos que essas 
imagens estão reunidas sob o título \#modernidadeespanhola, poderemos também supor que se trata da criação de um evento.

A profusão de imagens, seja do próprio espectador ou do espaço expositivo, contribuindo institucionalmente ou não, faz refletir sobre como o espectador de hoje interpreta a exposição de arte (incluímos aí a obra, o artista e o espaço expositivo). Sobre esse acúmulo de imagens produzidas por "amadores", Paula Sibília argumenta:

Não é fácil compreender para onde aponta essa estranha conjuntura, que, mediante uma incitação permanente à criatividade pessoal, à excentricidade e à procura constante da diferença, não cessa de produzir cópias descartáveis do mesmo (Sibília, 2008, p. 9).

Por outro lado, não podemos deixar de notar que, em meio à produção de imagens semelhantes, há uma narrativa sendo criada a partir da forma de ver de cada espectador. Giselle Beiguelman (2014) fala das imagens em circulação nas redes sociais e propõe a reflexão sobre uma estética que emerge no contexto atual. Para Beiguelman, essas imagens "colocam em curso um processo de canibalização da tela a partir do qual outras estéticas emergem, e também novos protagonistas" (BEIGUELMAN, 2014, p. 24). É nesse sentido também que este estudo procura seguir, buscando compreender o olhar sobre essa atitude cotidiana de registrar e produzir imagens na sociedade contemporânea.

\section{CONCLUSÃO}

As tecnologias de produção de imagens cada vez mais se mostram como o modelo dominante de visualização. Se o espaço, público ou não, tende a ser, como nos lembra Bruno Latour, "artificialmente mantido", "habilidosamente encenado" ou "inteligentemente elaborado" (LATOUR, 2014) por meio do design e das novas tecnologias, o espaço do museu não será diferente.

Ao focar nesse espectador que circula no espaço expositivo, agora não só com câmera fotográfica, mas com um dispositivo móvel que o conecta às suas redes sociais, confrontamos o problema da autenticidade da exposição e a questão da experiência presencial deslocada para o espaço virtual.

Pensando no conceito benjaminiano de aura, perguntamos se esta estrutura de imagens agrupadas no Instagram estaria retirando da exposição seu valor original ou autêntico? Em outro sentido, qual seria, em nossos dias, o valor do "aqui agora" de uma exposição? Não se trata de estabelecer a prevalência de uma experiência sobre a outra, mas de focar em outros modos de ver a arte e pensar nesse espectador que emerge no contexto das novas tecnologias. No 
entanto, se não afirmamos que o espectador contemporâneo tem sua fruição ampliada por esses dispositivos tecnológicos, notamos também que não cabe reduzir as imagens a meras exposições de si mesmo ou, esvaziá-las de um modo de subjetivação. $O$ deslocamento do modo como sujeito moderno percebe os objetos e o espaço que ocupa, ocorre em determinados períodos em que a técnica começa a mediar alguns estímulos, o cinema, como dito por Walter Benjamin (1987), é um exemplo disso.

O espectador, em outros momentos da história da arte, já foi ativado por outros dispositivos, seja pelo design de exposição - as exposições organizadas por Duchamp - ou fazendo parte da própria obra de arte, como em Cosmococas, de Helio Oiticica. Esse abordagem não é nova, mas buscamos aqui enfatizá-la no contexto do surgimento das novas mídias como o Instagram.

No momento em que as ideias e informações em torno da exposição de Pablo Picasso e a Modernidade Espanhola se concluíam, outra exposição foi inaugurada com o nome Frida Kahlo: conexões entre mulheres surrealistas (Caixa Cultural Rio de Janeiro, 2016). Dessa mostra, várias hashtags foram criadas, e em especial acessamos a tag \#mulheressurrealistas, com cerca de 1.200 posts. As imagens ali postadas formam um acervo de fotos belíssimas, nas quais é possível analisar todos os conceitos vistos aqui: composição, apelo institucional e, sem dúvida, o autorretrato.

O que percebemos no fluxo das imagens compartilhadas da exposição é um observador que participa da construção de seu espaço, seja ele físico ou nas redes sociais. O observador do qual falamos torna explícito os aparatos tecnológicos que podem transmitir, com ele, a experiência vivida. As imagens da exposição aqui apresentadas refletem o que foi produzido na interação entre o espectador e o aplicativo e deixa o registro do que foi a exposição do artista Pablo Picasso no Rio de Janeiro. Se ainda nos resta indagar se essas imagens dizem mais sobre o próprio espectador do que as obras ou do que a exposição, convém destacar, inicialmente, que indicam novas propostas de interação por parte dos museus. Será válido refletir ainda como essa autoconstrução do espectador pode estar sugerindo um reordenamento das diversas tecnologias em função do sujeito observador e como a contemplação de uma obra de arte por estar sendo transformada por essa relação. Por enquanto, parece correto afirmar que o público de exposição aprova as novas propostas de interação por parte dos museus. Além disso, analisar essa nova relação entre o espaço expositivo e o espectador, interligada pela tecnologia, pode ser o melhor caminho para pensar novas estratégias de expor a arte combinada com os novos meios pelos quais ela pode circular. 


\section{REFERÊNCIAS BIBLIOGRÁFICAS}

\section{Livro}

BEIGUELMAN, Giselle. Reinventar a memória é preciso. In: BEIGUELMAN, Giselle; MAGALHÃES, Ana (Org.). Futuros possíveis: arte, museus e arquivos digitais. São Paulo: Petrópolis, 2014.

BENJAMIN, Walter. Obras escolhidas: Magia e técnica, arte e política. São Paulo: Brasiliense, 1987.

BORJA-VILLEL, Manuel; PEIRÓ, Rosario. Picasso e a modernidade espanhola (19101963). In: CARMONA, Eugenio. Catálogo Picasso e a modernidade espanhola. Rio de Janeiro, 2015.

CRARY, Jonathan. Técnicas do observador: visão e modernidade no século XIX. Rio de Janeiro: Contraponto, 2012.

Suspensões da percepção: atenção, espetáculo e cultura. Tradução: Tina Montenegro. São Paulo: Cosac Naify, 2013.

DEBORD, Guy. A sociedade do espetáculo: comentários sobre a sociedade do espetáculo. Rio de Janeiro: Contraponto, 1997.

GROSSMANN, Martin; MARIOTTI, Gilberto (Orgs). Museu arte hoje. São Paulo: Hedra, 2011.

KRAUSS, Rosalind. Under the blue cup. The MIT Press, 2011.

MANOVICH, Lev. The language of new media. Cambridge, Mass.: MIT Press, 2001.

O'DOHERTY, Brian. No interior do cubo branco. A ideologia do espaço da arte. São Paulo: Martins Fontes, 2002.

SENRA, Stella. Prefácio. In: CRARY, Jonathan. Suspensões da percepção: atenção, espetáculo e cultura. Tradução: Tina Montenegro. São Paulo: Cosac Naify, 2013.

SIBILIA, Paula. O Show do eu: a intimidade como espetáculo. Rio de Janeiro: Nova Fronteira, 2008. 
SONTAG, Susan. Sobre fotografia. São Paulo: Companhia das Letras, 2004.

STEFANER, Moritz. Visual tool for the sociosemantic web. University of Applied Sciences Potsdam, 2007.

WISER, Mark. The Computer for the 21st Century. Scientific american. 1991. v. 265, n. 3, p. 94-104.

\section{Textos em meios eletrônicos}

IBRAM. Portal do instituto brasileiro de museus. Exposições brasileiras figuram em ranking das mais visitadas de 2015. Disponível na internet por http em:<http://www.museus.gov.br/exposicoes-brasileiras-figuram-em-rankingdas-mais-visitadas-de-2015/>. Acesso em 15 mai. 2016.

LATOUR, Bruno. Um Prometeu cauteloso? Alguns passos rumo a uma filosofia do design (com especial atenção a Peter Slotedijk). Palestra para o encontro Networks of Design, da Design History Society. Falmouth, Cornualha, 3 de setembro de 2008. http://filosofiadodesign.com/wp content/uploads/2014/10/ Prometeu-cauteloso.pdf

OXFORD Dictionary. Disponível na internet por http em: http://www. oxforddictionaries.com/us/definition/american_english/selfie. Acesso em 14 mai. 2016.

STATISTA. The statistics portal. Disponível na internet por http em: http://www. statista.com/statistics/253577/number-of-monthly-active-instagram-users/. Acesso em: 16 mai. 2016. 
Marcos Martins é professor da Escola Superior de Desenho Industrial ESDI/ UERJ, onde é atualmente Chefe do Departamento de Programação Visual. Graduado em Programação Visual pela Pontifícia Universidade Católica do Rio de Janeiro, mestre em Computer Art - School of Visual Arts, New York, EUA e doutorado em Comunicação pela Universidade Federal do Rio de Janeiro. Têm experiência em design gráfico e de interação, com ênfase nas áreas de design de interface e design editorial para exposições de arte. Como professor, seus principais campos de pesquisa são design de interação, estudos midiáticos e interseções entre Arte e Design. Co-editou o livro "Dispositivo Fotografia e Contemporaneidade"(Rio de Janeiro: Nau, 2013)

Renata Perim cursa doutorado em Design na Escola Superior de Desenho Industrial ESDI/UERJ pesquisando a área de design de exposição e o espectador mediado pelas tecnologias de produção de imagens. É mestre em História e Crítica da Arte pela UFES e graduada em Artes Visuais pela mesma instituição. É diretora de arte e tem experiência em design gráfico e digital. Atualmente é professora nos cursos de Design Gráfico e Publicidade e Propaganda no Instituto de Tecnologia Infnet - RJ.

Recebido em: 11/08/2016

Aceito em: 17/11/2016 